\title{
Mirror Psycho-Pedagogy in the Population with Severe Intellectual Disability and Severe Autism (SIDSA)
}

\author{
Giuliana Galli Carminati1,2 (ㄷ, Federico Carminati2 \\ ${ }^{1}$ Seoul National University (Bundang Hospital), Seoul, Republic of Korea \\ ${ }^{2}$ International Society of Multidisciplinary Psychoanalysis, Geneva, Switzerland \\ Email: giuliana.gallicarminati@gmail.com
}

How to cite this paper: Carminati, G. G., \& Carminati, F. (2021). Mirror Psycho-Pedagogy in the Population with Severe Intellectual Disability and Severe Autism (SIDSA). Psychology, 12, 43-58. https://doi.org/10.4236/psych.2021.121003

Received: November 2, 2020

Accepted: January 10, 2021

Published: January 13, 2021

Copyright $\odot 2021$ by author(s) and Scientific Research Publishing Inc. This work is licensed under the Creative Commons Attribution International License (CC BY 4.0).

http://creativecommons.org/licenses/by/4.0/

(c) (i) Open Access

\begin{abstract}
In this paper we discuss at first the clinical case of a person affected by severe mental disability and severe autism (SIDSA). From this specific case we extend our reasoning to the whole population affected and we express some simple rules that should be applied to care for this very difficult population in care homes and specialized institutions. We underline the need for this population to be protected from stress factors, which can be very damaging for their well-being and quality-of-life. Lastly, we describe an approach to activities in sheltered workshops and residential institutions that we call mirror psycho-pedagogy. This approach that we have validated on several occasions in our professional experience, has been defined in analogy to the mirror neuron theory, and has shown its validity in dealing with the stress of these people related to their performance facing the daily activities in which they are engaged.
\end{abstract}

\section{Keywords}

Severe Intellectual Disability, Severe Autism, Autistic Spectrum Disorders, Sheltered Workshops, Occupational Care

\section{Introduction}

The population affected by Severe Intellectual Disability and Severe Autism (SIDSA) presents specific and substantial challenges to caregivers. Since the aetiology of SIDSA is still not well known, and it is almost certainly multiple, its prevention and cure are beyond the possibility of today's medicine. It is therefore essential to concentrate on the improvement of their Quality of Life (QoL). 
Their little or no verbal skills and their extreme sensitivity to environmental stress create substantial difficulties both for protected workshop activities and classical psychotherapy. During our multi-decennial experience treating people with SISDA we have elaborated a method that we call Mirror Psycho-pedagogy aimed at specifically addressing this population in its specificity.

At first, we present a clinical case illustrating the typical journey of these persons. We have opted for a rather detailed description since it is important to realise how the quality of life of these persons is often-and despite the good will and dedication of all intervening part-severely degraded by the successive interventions and superposition of different actors.

We follow up by describing what should be, based on our experience, the most important features of a caregiving environment tailored to these persons. We underline the fact that, given the vulnerability of these persons to any situation they find distressing, the improvement and preservation of their Quality of Life is dependent on reducing their stress and providing the most predictable and relaxing environment possible. We lay out some basic principles and how these should be applied to the everyday institutional organisation.

We then describe our method, and we try to provide some theoretical basis for our empirical observations. Without pretending to provide a full theoretical foundation, we recall the mirror neuron theory and the broken mirror theory that has been proposed by many authors to explain some of the aetiology and symptomatology of SISDA. We conclude with some general recommendations on the care infrastructure to treat these patients.

\section{The Story of Pierre-Yves}

Pierre-Yves (not the real name of the person) is a 30 -year-old man, admitted since adolescence in a socio-educational structure, Beau Lac (fictional name) in a Swiss Canton, at first in a sheltered workshop and then as resident. His mother was 35 years old and his father 36 when he was born and is three older siblings-a sister and two brothers his senior by 6, 4 and 2 years respectively-lived in the parents' family house, a large farm, together with his maternal grandparents.

His birth was problematic since it happened one month early, and the delivery had been difficult due to the abnormal positioning of the foetus. The memories referred by the parents are unclear and dominated by the feeling of danger and haste. The child was in the incubator for a month and the doctors reported severe hypotonia.

Pierre-Yves had difficulty eating, then had difficulty sitting and he could walk only at 2 and half, he was not able to speak, the language being reduced to a few words- "mom, drink, good coffee".

The parents decided to keep him at home, refusing institutional placement. Pierre-Yves participated in activities in a specialized school, four days a week, until aggressive behaviour towards himself and especially towards the mother made the situation untenable at home, the brothers being also troubled by the agitation and the reactions of anger of the younger brother. The sister, having 
married, lived in an apartment in the same farm and she was therefore less confronted with her brother's behaviour. The birth of the little nephew was the trigger that decided the parents to ask for institutionalization. Although with great reluctance they had to admit being afraid that Pierre-Yves could, unwittingly, harm the new-born.

The integration of Pierre-Yves into the Beau Lac residence was not without difficulty. Pierre-Yves did not understand why he had to return to the Institution after spending the weekend with his parents. The behaviour at home and especially in the car during the trip back to Beau Lac became nightmarish, and the educational team asked to the parents to pace the weekends with the family. Nevertheless Pierre-Yves remained often tense and difficult to manage, upon his return to the residence, for a good half of the following week.

Pierre-Yves no longer seemed to know where he was, either with his parents or at Beau Lac. The episodes of restlessness at home, in addition to when he returned the Institutions, were becoming more and more frequent.

Psychotropic medication was extensively discussed with the parents-who acted as Pierre-Yves' "general guardians" and were therefore responsible for his medical care-but they refused the administration of an antipsychotic while they had accepted treatment with benzodiazepine and sedatives, which resulted in a very modest improvement in the crises.

Involuntary hospital admission into the psychiatric unit at the Cantonal Psychiatric Center (known as CPC) led the distraught parents to accept antipsychotic treatment because the socio-educational team refused Pierre-Yves' return to Beau Lac without treatment. We note that Swiss law allows involuntary hospitalization into a psychiatric unit only if there is the concomitant presence of danger, urgency and psychiatric disorders.

Antipsychotic therapy for non-verbal persons is often used more for its sedation side effects than for the antipsychotic effect. In these persons, the psychotic symptoms are very difficult to detect, and consequently also their improvement is very difficult to assess.

Pierre-Yves returned to his institution after more than two months of hospitalization. Home visits were drastically reduced to once a month, Saturday until Sunday noon with only one night at the parents' home. Apart from a certain slowdown and a very slight decrease in temper tantrums, Pierre-Yves' situation was not changed. The psychiatrist who consulted at the institution slightly increased the antipsychotic treatment because the socio-educational team found it increasingly difficult to endure the anger episodes that were still present. One source of stress and tantrums was the travel between the Institution and the sheltered workshop. To reduce the problem, it was proposed to keep Pierre-Yves at the Institution and to have him participating in some activities in place. This proposal was however refused by the supervisory body because they noted that he was calmer in the workshop-probably due to the structuring of the activities there-and because they were not convinced by the activities that the educational team proposed for him at the Institution. The most important concern re- 
mained how to get him safely from the Institution to the workshop, the reverse trip seeming to be less problematic.

The canton's policy is very strict on the maintaining workshop activities and the supervisory body, intervened in this difficult situation, urging the teams to continue these activities.

The consultant psychiatrist proposed a moderate reduction of the activities in the workshop to reduce the stress of the journeys that monopolized at least two educators to accompany him, but the reaction of the supervisory body was uncompromising, stating that "confinement" in the residence was not "ethically acceptable": the workshop activities being considered "fundamental for social integration and personal empowerment".

Pierre-Yves therefore kept traveling between his residence and the workshop with tantrum crises every two days, which left to the consultant psychiatrist no choice but to increase the sedative treatment and to request three other hospitalizations at the CPC.

Hospital psychiatrists, not knowing what else to do for this person, other than minimally retuning the treatment, tended to discharge him after a couple of days or to forget him in their hallways, which however did not seem to displease him at all. Indeed, Pierre-Yves was much calmer within the certainly strict but very quiet environment of the psychiatric ward.

After about two and a half years of psychotropic treatment, somatic disorders started to appear, or perhaps they were already present but undetected, and they focused the attention of the educators, still looking for the reasons for Pierre's outbursts of anger.

These disorders mainly concerned the gastrointestinal situation, particularly in the form of constipation which was in fact difficult to assess precisely because the control of the stool was laborious and often impossible.

This physical discomfort, the presence of noisy residents and some episodes of aggression toward them had forced the implementation of a measure of constraint. It was a classic situation of "the cat biting her tail": the somatic discomfort generated anger, which was sedated with psychotropic drugs, which caused constipation, therefore somatic discomfort and so on.

Cantonal legislation extends the permission to apply coercive measures also to non-hospital environments. For both environments the application of these measures is very strictly regulated, and their application outside hospitals is also a source of constant discussion between professionals and politicians. These measures, in the case of Pierre-Yves, began to become a daily need. This situation offended the parents who saw in this a form of imprisonment and they decided to alert the supervisory body. This resulted in a stern rebuke for the consultant psychiatrist, the responsible educators and the pedagogical director, accompanied by the threat to bring the whole matter to the attention of the cantonal disciplinary commission for medical affairs.

The consultant psychiatrist therefore decided-and made ubiquitously known - that he would no longer sign the restraint measures, directly sending 
Pierre-Yves to the hospital psychiatric ward. The educational team, for once, agreed with the consultant psychiatrist because nobody fancied receiving an official blame or losing the place of work. Pierre-Yves broke all the records for the number of return trips to the CPC.

Hospitalizations were overwhelmingly short, the CPC being subject to cantonal "efficiency and economy" requirements, with a notable intensification of more or less collegial telephone exchanges between CPC psychiatrists and the consultant psychiatrist of Beau Lac.

Alarmed by the situation, the family asked for a meeting with the pedagogical director and the consultant psychiatrist who quite simply underlined their dead-end situation, stuck as they were between the impossibility of using restraint measures-denounced by the family itself and deemed excessive by the supervisory body-and the increasing number of shorter and more frequent hospitalizations at the CPC, which were increasingly frowned upon by the authorities.

The family, seeing that their "combative" attitude did not yield positive results, decided to ask the supervisory body to provide additional personnel to Beau Lac to address Pierre-Yves' needs. Beau Lac pedagogical director and the consultant psychiatrist had therefore to write a detailed justification, followed by a counter-request from the supervisory body for a more detailed document, followed by the exchange of several increasingly detailed reports to finally reach an agreement: an extraordinary allocation of a half-post of educator over a period of three months, subject to even more detailed reports describing the situation and the evolution of Pierre-Yves' needs.

Pierre-Yves was absorbing a considerable amount of time on the part of the educational teams and the consultant psychiatrist, unfortunately but inevitably to the detriment of the other residents.

Cantonal policy required the workshop activities to continue at all costs, the related tantrum explosions following one another, with repeated assaults on other residents and now complaints from other families who were beginning to no longer accept finding their children with beating marks. The presence of the additional half-time educator helped only partially. Pierre-Yves, despite being followed by a person "for him" for a part of the activities in the residence and in the workshop, was quickly tired, did not want to do anything, neither in the workshop nor in the residence, went around in circles, getting quickly upset and having frequent explosive outbursts of anger.

As the coercive measures could no longer be applied, traditional workshop activities became impossible because Pierre-Yves got rapidly bored of them. The situation in the residence remained tense with the other residents in a state of continuous alert: the improvement hoped for from the "extraordinary measures" put in place by the supervisory body did not materialize. The reports, although detailed at will, were of a repetition that bordered on the copy-paste and the whole team disinvested this difficult resident, always so explosive and source of worry. 
The exceptional measure granted by the supervisory body were withdrawn after eight months "for lack of efficiency" and the family, by exhaustion, accepted a hospitalization that was announced as "long" and was agreed after a negotiation in high places. Beau Lac could no longer accommodate Pierre-Yves and the CPC therefore remained the only place where to keep this young man.

There is no moral to this story, it describes, except errors and omissions, a situation that we have invented as a mixture of many real situations, and in which the psychiatrist, educational and nursing staff can easily recognize themselves, we are sure of it.

\section{A Modest Proposal}

What follows is a modest proposal, in theory and practice, of structuring psycho-educational activities that can be done in residential institutions, sheltered workshop and even in family, which help to relax and calm persons with specific needs while maintaining a link with the people in charge of their care. To avoid overloading the text with two personal pronouns, we are consistently using the masculine one, but we of course intend to refer to both genders.

This brief note, in fact, aims to suggest a possible-and relatively easy-solution to situations in which subjects with Severe Intellectual Disability and Severe Autism (SIDSA) become very difficult to manage in a socio-educational environment and are therefore led to experience long hospitalizations in a psychiatric environment that, without dramatizing the occurrence of a hospital stay, should anyway be few as possible and not exceeding a couple of weeks.

Severe autism is very difficult to differentiate from severe/profound mental disability because the autistic triad (impaired communication, impaired social skills and abnormal sensory perceptions) is present in both situations. Severe autism affects around $0.1 \%$ of the general population (Durkin et al., 2008, 2010; Fombonne, 2009; Grether et al., 2009, King \& Bearman, 2009; Rice, 2013; Rice et al., 2013; Schieve et al., 2011; Wing \& Potter, 2002) and requires intensive psycho-educational care and an expensive human and economic commitment (Hewlett \& Moran, 2014; Honeycutt et al., 2004; WHO, 2006; Pinheiro et al., 2017; Trautman et al., 2016). We define this population with Severe Intellectual Disability and Severe Autism (SIDSA) considering the severity of intellectual disability and the severity of autism spectrum disorder.

There is a form of inconsistency between the relatively small number of people affected by this disorder and the economic and organizational investment necessary to offer them a minimal quality of life. Another inconsistency is that, due to their inability or extreme poverty of language, their quality-of-life rests upon the judgment of others (Galli Carminati et al., 2017). In addition, ideals of self-determination, social integration, activity if not productive, at least sheltered, often grounded in the best humanistic intentions of respect for the population with disabilities (in the general sense), risk to become for this specific population-given its lack of anticipation and adaptability to changes as well as its almost neurological vulnerability to stress-a source of maladaptation, stress 
and-ultimately-reduced quality of life.

Here we see another inconsistency: what is good and fair for a large part of the disabled population, could become a form of ill-treatment for the SIDSA population, admittedly small and eminently incapable of expressing its opinion (Brown \& Brown, 2003; Schalock et al., 2002; Schalock, 2005; Verdugo et al., 2005; Bertelli \& Brown, 2006).

Another important and problematic point is that the SIDSA population, which does not have the discernment to give informed consent to either psycho-educational or pharmacological research, is orphaned from serious studies because, in view of the legal difficulties, inspired by standards designed for the protection of persons, very few researchers venture into protocols that take significant time and energy and not to easily attract funds given the reduced concern toward very small population.

Most studies are dedicated to similar-but different-disorders such as Asperger syndrome or children autism (Egilson et al., 2017; Joshi et al., 2014; Siebes et al., 2018; Woltenscroft et al., 2018; Zimmerman et al., 2018) that have a much higher "mediatic attractiveness".

The result of the difficulty in studying this population is that the psycho-educational paradigm applied is often widely borrowed from other populations that are clearly less affected and more independent. For the same reason-lack of specific studies on this difficult population-psychopharmacological treatments are largely inherited from the general psychiatric population or from child psychiatry (Aman, 2010; Aman et al., 1985a, 1985b; Fombonne et al., 1995, 2009; Holland \& Wainer, 2012).

To return to the psychoeducational practice, it is central to highlight the difficulties of adapting to daily reality for the population with SIDSA. In addition to the difficulty of social and verbal communication, this population needs a predictable and repetitive environment that can reassure the person about the daily sequence of activities. It is useless, even dangerous for the mental health of the population with SIDSA, to pretend to apply psychoeducational criteria that do not belong to them, such as the variety of activities, the concept of novelty and sensory stimulation, if not with great moderation and with respect for their specific needs and limitations. In detail, this translates into the need for:

1) A predictable and reassuring environment.

2) Repetitiveness.

3) Calm intended as absence of specific stress-factors.

4) Periods without sound and sensory stimulation.

We now describe each point in detail.

\subsection{A Predictable and Reassuring Environment}

If we consider the equivalent mental age of this population, we cannot imagine that a 2 - 3-year-old child can participate in playing activities without proper breaks and with summary information about what is happening or will happen. In addition, such a child feels protected by the almost constant presence of the 
parents and this allows him to gradually adapt to other people, given the necessary time.

A person with autism who lives in contact with an often-changing socio-educational team will not have the same ability to adapt to other people, lacking the stable and reassuring support of a presence comparable to that of the parents. Changes of location, for example between apartment and workshop, must also respect the need for a predictable and reassuring environment (McGill et al., 2020; Iversen et al., 2019; Burke \& Cocoman, 2020).

The start of the activities in the sheltered workshop therefore requires getting used to the environment, which must be done in the company of a well-known educator from the apartment. The well-known educator and must remain at least half an hour in the workshop with the person acting as a transitional object, so that the person can get used to the new place.

It is very helpful if the person brings with him from the residence a bag or backpack to leave at the entrance to the workshop. This may act as a substitute transitional object when the well-known educator stops accompanying him after a couple of weeks. The multiplication of different places and environments is to be avoided; if we add the family home for the weekends, together with the apartment and the workshop we already have three places, which is a lot. Any increase in this number, pool, gym, restaurant or other, must be introduced with care. When a new place is added, the first activities in this place should be brief and preferably in presence of a well-known educator and accompanied by a small snack (cookies and/or fruit) and a drink taken while sitting.

This careful approach is neither unnecessary nor avoidable because the of carelessness are an anxiety episode or a clastic crisis and the resulting intake of pharmacological reservations. Getting used to a new place should be done over at least ten times, always in the same way, then the new activity can in principle begin.

The gradual introduction of a new activity, which results in gradually increasing-therefore with a different pattern each time-is a false good idea because the person is confronted by too many changes. A simple first step with a well-known educator, with snack and drink, repeated for about ten times, followed by regular activity, should be enough.

\subsection{Repetitiveness}

For the reasons briefly stated above, it is important that the day's activities and the waking up and going to bed rituals are repetitive to allow the person to be reassured by finding time and space landmarks that can be vicarious of the inevitable instability of the socio-educational team (Iversen et al., 2019; Mansell et al., 2008).

\subsection{Quiet}

Moments of quiet should punctuate the day, for example with a drink break at 10 a.m., a nap after the midday meal and a break at 4 p.m.. It would be prudent 
to also take a drink break before leaving the workshop to return to the residence.

\subsection{Moments without Sound and Sensory Stimulation}

Due to abnormal sensory perceptions, it is important to give moments of sensory pause, during the nap and before bedtime. The moment of awakening must be organized very gradually with a responsible educator, therefore well-known by the person, waking him up and returning after a quarter of an hour to get him up. Waking up in a hurry is almost a sure sign of a hectic day. Breakfast should be eaten before shower to avoid hypoglycaemia and to approach the relatively difficult time of evacuation and personal hygiene in the best possible physical shape.

We now turn our attention to the daily activities because careful attention must be given to the content of the activities that can take place in the apartment or in the workshops. Each activity should be done in only one place to avoid confusion (Adams, 2017; Reichler \& Schopler, 1976; Stoppelbein et al., 2016), for example doing the puzzles in the residence and storing objects in the workshop can make a difference already sufficient to avoid confusion. If the person can perform an activity on his own, the sequence of actions should be designed in such a way as to allow maximum predictability to overcome his difficulties in anticipation.

When the person is in a period of adaptation, or of difficulty, or going through a crisis, it is wise not to add a place (the workshop in particular) and to keep activities in the apartment. Activities in this delicate situation can be especially difficult to do alone and the person should be accompanied by an educator, if possible, already known to him.

\section{Mirror Psycho-Pedagogy}

We want now to introduce a specific psycho-therapeutical approach that in our practice has demonstrated its utility. There are situations with this kind of persons where the mere execution of an activity brings enormous, almost unbearable, frustration and stress, since the person does not feel capable of doing it. These situations are usually prodromic to panic attacks and often rage outbursts and inappropriate or aggressive behaviour. In the most serious situations, this may lead to real crises with subsequent hospitalisation. Many months of patient work can be "lost" in a moment and the person may find himself ${ }^{1}$ back to where he was long time ago. These occurrences cannot be totally avoided with this population, but we have noted that the educator can soften their impact by a technique that we call mirror psycho-pedagogy in analogy with the mirror neurons (Rizzolati \& Craighero, 2004; Keysers, 2010). In this we also refer to previous authors who have proposed a connection between mirror-neuron disfunction and autism (Oberman et al., 2005; Dapretto et al., 2006; Oberman et al., 2008; Perkins et al., 2010).

${ }^{1}$ To simplify the writing we use, as customary in the English language, the masculine pronoun. What we write does apply of course to both genders. 
In situation of crisis, the activities are especially difficult, as the person is faced with his partial or total inability to carry out the proposed exercises, even if he has chosen them. Frustration with this inability frequently results in a tantrum (Berkovits et al. 2016; Gourash, 2017; Torrado et al., 2017). When in crisis with agitation, great anxiety and aggression towards oneself or others-situations well known to the socio-educational teams who take care of this population-the person needs to structure himself in an activity but cannot bear the frustration of failing in it: it is here that the mirror psycho-pedagogy can be conveniently used. The educator can sit next to the person and do an activity himself (puzzle, arrangement by shapes and colours, etc.). He will verbally comment on what he is doing by underlining with gesture and pointing to the object or piece of the puzzle, describing the colour and shape or image of the piece of the puzzle. He will touch and give the object to the person to handle.

Our clinical experience suggests that this activity should be performed with as much peace of mind as possible and will be complemented by a cup of coffee or tea, or a drink, as well as some cookies or fruits. Calmness and repetitiveness in the activity are the keystones of success. As far as possible we could try to repeat the same gestures in the same order, but this requirement should not stress the educator, because it is the fact of being at ease that allows him to put at ease, mirroring one might say, the person.

In mirror psycho-pedagogy the educator works "via" the person and vice versa. The point to underline is that the person looks at the educator who is doing the exercise and participates by watching and accompanying him or even repeating his gestures, but with no pressure of "succeeding" in the exercise, since it is being done by the educator himself and therefore, it cannot "fail".

We can relate these observations to the so-called broken mirror hypothesis. This theory (Oberman \& Ramachandran, 2007), in essence, supposes a correlation between a disfunction of the mirror neuron system and autism spectrum disorders. Since its appearance on the scientific scene, this theory has been refined and developed by several scholars and there are now two main derived models: the EP-M (emulation and planning-mimicry) model (Hamilton, 2008), the social top-down response modulation model (STORM) (Wang \& Hamilton, 2012; Hamilton, 2013).

Experimental studies on these different theories (see Yates \& Hobson, 2020) with a variety of methods-including EEG, neurofeedback and also post-mortem exams-have hitherto failed to provide a clear proof in favour of the broken mirror hypothesis or one of the two main models. Moreover, most of the studies concern persons with a reported IQ greater than 70, who cannot be considered intellectually disabled, as it is the case for the SIDSA population we consider in this work.

Despite the above, we find that the broken mirror hypothesis provides an interesting, albeit qualitative, key to interpret our clinical observations and to support our therapeutic approach. It is our experience that the person, when confronted to an activity that he thinks too difficult, feels a paralyzing frustra- 
tion that leaves him no alternative but an outburst of rage and impotence. He knows what is supposed to do, but the greater the fear of failing, the more intense the anguish that paralyzes him. We suppose that by seeing the exercise performed by the educator, the person's neurons that were paralyzed by anxiety get activated by the mirror effect, and the person overcomes the paralysis, as his nervous system actually does what he before considered impossible. We have observed that this provides him with a sense of fulfillment and the paralyzing anxiety of failure is largely dissipated. Of great importance is the attitude of the educator, who should not be confrontational but open and inclusive, he should not be "teaching" how to do the exercise, but just "do it with" the person, whatever his participation is.

The situation of calm and relaxed activity is fundamental to allow the mirror psycho-pedagogy to succeed. This technique can be carried out individually or in groups (Galli Carminati et al., 2004; Legay et al., 2003), which is also "economically" effective, because an educator can work with and provide a reassuring and supportive framework to several people, even in crisis. This also prevents the well-known problem of socio-educational teams of having to cope with crisis situations in a one-to-one setting, which makes it very difficult to revert to a less exclusive presence even when the crisis is surmounted.

People with a very limited intellectual level and autistic disorders indeed have a remarkable capacity to work in groups (Galli Carminati, 2003) provided that the framework is predictable, stable and calm. For example, the fact of passing from one person to the other in the group the object or piece of the puzzle to be inserted can also help them to learn and apprehend the presence of the other and to tolerate and appreciate the exchange and contact with each other. In our opinion, it is important that the educational teams can use this approach of soft activity both in the residence and in the workshop, respecting, as we said above the difference of activities-for example puzzle in residence and storage in the workshop-to avoid any possibility of confusion. Indeed, the mirror activity can be extended to the workshop, always by differentiating it, after the situations of adaptation, difficulty or crisis, have been overcome.

We have observed that it is important to understand that wanting to go faster than the person's ability to adapt leads to considerable loss of time and real suffering and can also chronicize the person's difficulties. The transition from activities in residence to activities in workshops must therefore not be influenced by anything other than observation of the person and his well-being. Philosophical constructs or political exigencies, no matter how well-meaning, should not interfere in the care of the person.

There are important implications of the above. We think that perhaps the most important one is the necessary shift by families and caring staff from a performance to an achievement perspective. This seems obvious for SISDA persons, however too often the "measure" of the well-being of the SISDA person is more what he manages to achieve during his activities in the residence or sheltered workshop, than his quality of life. Sometimes this is at the expenses of the 
quality of life itself, however well-meaning and dedicated all the participants are. This is a result of the high ethical value attributed by our society to work and autonomy. However, for the SISDA population, these lofty goals should not be achieved at the expenses of their happiness, requiring, as often is the case, additional medication to achieve what we judge to be their goals. Only an impartial approach centred on the person and an essential acceptance of his diversity can bring benefits to his quality of life. These considerations have also a social aspect, as much value has been given - and for excellent reasons-to the integration of the person with handicap in a "normal" working environment. While we should not lose sight of this goal, which has brought a substantial advance in the recognition of the dignity and rights of this population, we should also never forget to consider the unicity of each individual and his specific needs and possibilities.

The second major consequence is economic and social. Making sure that the environment is stable, including the caregivers, runs against the increasing precarity and fast turn-around of the health care staff. If we want to make sure that health care personnel (doctors, psychologists, nurses, educators and so on) are stable and have long careers in the same position, we must protect them too from work-related stress and provide them with a fulfilling work environment with appropriate career opportunities. This seems to be problematic in the current socio-economic environment, given the rising costs of health care. A complete discussion of these elements goes beyond the scope of this paper, and we have just given some lines of thought.

\section{Conclusion}

We have described a fictional but realistic case representing several real stories that we have encountered in our professional experience of treating people with severe intellectual disability and severe autism (SIDSA). We have detailed a strategy to deal with these difficult cases based on stress avoidance, stability and predictability of the environment and appropriate balance between stimulating activities and moments of peace and relaxation. We have explained as the focus should be on the quality-of-life of these persons rather than on any assumed need for autonomy or activity. The well-being of the person should be, in all cases, the guiding principle governing the activity of the caregivers. Lastly, we have described how the mirror-neuron mechanism can guide the caregivers, in particularly the educators, to perform the activities at the sheltered workshop or at the residence in such a way as to minimize his anxiety and reduce the danger of anger outbursts and consequent hospitalisations in the psychiatry ward. We have also explained how these activities can be carried on in groups making them more economically viable without detracting from their efficacy.

\section{Conflicts of Interest}

The authors declare no conflicts of interest regarding the publication of this paper. 


\section{References}

Adams, D. (2017). Behavior Supports and Instructional Strategies for Students with High Functioning Autism in the Inclusive Elementary School Classroom. http://csusmdspace.calstate.edu/bitstream/handle/10211.3/198291/AdamsDana_Fall20 17.pdf

Aman, M. G. (2010). Annotated Bibliography on the Aberrant Behavior Checklist (ABC), Unpublished Manuscript, Columbus, OH: Ohio State University. https://doi.org/10.1037/t10453-000 http://psychmed.osu.edu/media/ABC_Annotated_Bibliography_12-6-2010.pdf

Aman, M. G., Singh, N. N., Stewart, A. W., \& Field, C. J. (1985a). The Aberrant Behavior Checklist: A Behavior Rating Scale for the Assessment of Treatment Effects. American Journal of Mental Deficiency, 89, 485-491.

Aman, M. G., Singh, N. N., Stewart, A. W., \& Field, C. J. (1985b). Psychometric Characteristics of the Aberrant Behavior Checklist. Journal of Mental Deficiency, 89, 492-502.

Berkovits, L., Eisenhower, A., \& Blacher, J. (2016). Emotion Regulation in Young Children with Autism Spectrum Disorders. Journal of Autism and Developmental Disorder, 47, 68-79. https://doi.org/10.1007/s10803-016-2922-2

Bertelli, M., \& Brown, I. (2006). Quality of life for people with intellectual disabilities. Current Opinion in Psychiatry, 19, 508-513. https://doi.org/10.1097/01.yco.0000238479.81528.9f

Brown, I., \& Brown, R. I. (2003). Quality of Life and Disability: An Approach for Community Practitioners. London: Jessica Kingsley.

Burke, D., \& Cocoman A. (2020). Training Needs Analysis of Nurses Caring for Individuals an Intellectual Disability and or Autism Spectrum Disorder in a Forensic Service. Journal of Intellectual Disabilities and Offending Behaviour, 11, 9-22.

https://doi.org/10.1108/JIDOB-10-2019-0024

Dapretto, M., Davies, M. S., Pfeifer, J. H., Scott, A. A., Sigman, M., Bookheimer, S. Y., \& Iacoboni, M. (2006). Understanding Emotions in Others: Mirror Neuron Dysfunction in Children with Autism Spectrum Disorders. Nature Neuroscience, 9, 28-30. https://doi.org/10.1038/nn1611

Durkin, M. S., Maenner, M. J., Meaney, F. J., Levy, S. E., Di Guiseppi, C., Nicholas, J. S., Kirby, R. S., Pinto-Martin, J. A., \& Schieve, L. A. (2010). Socioeconomic Inequality in the Prevalence of Autism Spectrum Disorder: Evidence from a U.S. Cross-Sectional Study. PLoS ONE, 5, e11551. https://doi.org/10.1371/journal.pone.0011551

Durkin, M. S. M., Matthew, J., Newschaffer, C. J., Lee, L. C., Cunniff, C. M., Daniels, J. L., Kirby, R. S., Leavitt, L., Miller, L., Zahorodny, W., \& Schieve, L. A. (2008). Advanced Parental Age and the Risk of Autism Spectrum Disorder. American Journal of Epidemiology, 168, 1268-1276. https://doi.org/10.1093/aje/kwn250

Egilson, S. T., Ólafsdóttir, L. B., Leósdóttir, T., \& Saemundsen, E. (2017). Quality of Life of High Functioning Children and Youth with Autism Spectrum Disorder and Typically Developing Peers: Self- and Proxy-Reports. Autism, 21, 133-141.

https://doi.org/10.1177/1362361316630881

Fombonne, E., Achard, S., \& Tuffreau, R. (1995). L'évaluation du Comportement Adaptatif: l'échelle de Vineland (pp. 79-90). Paris: Centre Technique National d'Etudes et de Recherches sur les Handicaps et les Inadaptations.

Fombonne, E. (2009). Epidemiology of Pervasive Developmental Disorders. Pediatric Research, 65, 591-598. https://doi.org/10.1203/PDR.0b013e31819e7203

Galli Carminati, G. (2003). Le Groupe Arbres. In G. Galli Carminati, \& A. Méndez (Eds.), 
Groupes, Psychopathologie et Retard Mental. L'Expérience Genevoise (pp. 25-34). Genève: Médecine et Hygiène.

Galli Carminati, G., Carminati, F., Lehotkay, R., Lorincz, E. N., Subirade Jacopit, V., Rondini, E., \& Bertelli, M. O. (2017). Residential Placement and Quality of Life for Adults with Severe Autism Spectrum Disorders and Severe-to-Profound Intellectual Disabilities. Advances in Autism, 4, 187-205. https://doi.org/10.1108/AIA-01-2017-0001

Galli Carminati, G., Constantin, N., Legay, Y., Tschopp, B., Zid, L., Hermet, A., Thibault, P., Gorianz, P., Schaya, M., Levental, M., Carrel, C., \& Ritter, S. (2004). “Sonar Group” Underwater Music Therapy. Evolution of 2 Persons with Severe Disability on a Period of 3 Years. European Journal of Psychiatry, 18, 106-114.

Gourash, L. M. (2017). Understanding and Managing Emotional Outbursts and Tantrums in Autism Spectrum Disorder. Journal of the American Academy of Child \& Adolescent Psychiatry, 56, S45. https://doi.org/10.1016/j.jaac.2017.07.174

Grether, J. K., Rosen, N. J., Smith, K. S., \& Croen, L. A. (2009). Investigation of Shifts in Autism Reporting in the California Department of Developmental Services. Journal of Autism and Developmental Disorders, 39, 1412-1419.

https://doi.org/10.1007/s10803-009-0754-Z

Hamilton, A. F. D. C. (2008). Emulation and Mimicry for Social Interaction: A Theoretical Approach to Imitation in Autism. The Quarterly Journal of Experimental Psychology, 61, 101-115. https://doi.org/10.1080/17470210701508798

Hamilton, A. F. D. C. (2013). Reflecting on the Mirror Neuron System in Autism: A Systematic Review of Current Theories. Developmental Cognitive Neuroscience, 3, 91-105. https://doi.org/10.1016/j.dcn.2012.09.008

Hewlett, E., \& Moran, V. (2014). Making Mental Health Count: The Social and Economic Costs of Neglecting Mental Health Care, OECD Health Policy Studies. Paris: Organization for Economic Co-Operation and Development Publishing. https://doi.org/10.1787/2074319x

Holland, P., \& Wainer, H. (2012). Differential Item Functioning. Hillsdale, MI: Erlbaum Associates, Inc.

Honeycutt, A., Dunlap, L., Chen, H., Al Homsi, G., Grosse, S., \& Schendel, D. (2004). Economic Costs Associated with Mental Retardation, Cerebral Palsy, Hearing Loss, and Vision Impairment-United States. Morbidity and Mortality Weekly Report, 53, 57-59.

Iversen, T. E., Horndalsveen, K., Matre, E., Henriksen, T. F., Fusche, S., Kildahl, A. N., \& Bakken, T. L. (2019). Inpatient Treatment of Borderline Personality Disorder in Adults with Intellectual Disability: Reflections on Practice. Advances in Mental Health and Intellectual Disabilities, 13, 67-75. https://doi.org/10.1108/AMHID-03-2018-0008

Joshi, G., Faraone, S. V., Wozniak, J., Tarko, L., Fried, R., Galdo, M., Furtak, S. L., \& Biederman, J. (2014). Symptom Profile of ADHD in Youth with High-Functioning Autism Spectrum Disorder: A Comparative Study in Psychiatrically Referred Populations. Journal of Attention Disorders, 21, 846-855. https://doi.org/10.1177/1087054714543368

Keysers, C. (2010). Mirror Neurons. Current Biology. 19, R971-R973. https://doi.org/10.1016/j.cub.2009.08.026

King, M., \& Bearman, P. (2009). Diagnostic Change and the Increased Prevalence of Autism. International Journal of Epidemiology, 38, 1224-1234. https://doi.org/10.1093/ije/dyp261

Legay, Y., Galli Carminati, G., Tschopp, B., Zid, L., Hermet, A., \& Schaya, M. (2003). Le Groupe Sonar: Un Travail Thérapeutique Groupal en Milieu Aquatique. In G. Galli 
Carminati, \& A. Méndez (Eds.) Groupes, Psychopathologie et Retard Mental. L'Expérience Genevoise (pp. 35-44). Genève: Médecine et Hygiène.

Mansell, J., Beadle-Brown, J., Whelton, B., Beckett, C., \& Hutchinson, A. (2008). Effect of Service Structure and Organization on Staff Care Practices in Small Community Homes for People with Intellectual Disabilities. Journal of Applied Research in Intellectual Disabilities, 21, 398-413. https://doi.org/10.1111/j.1468-3148.2007.00410.x

McGill, P., Bradshaw, J., Smyth, G., Hurman, M., \& Roy, A. (2020). Capable Environments. In Press. Tizard Learning Disability Review, 25, 109-116. https://doi.org/10.1108/TLDR-05-2020-0007

Oberman, L. M., Hubbard, E. M., McCleery, J. P., Altschuler, E. L., Ramachandran, V. S., \& Pineda, J. A. (2005). EEG Evidence for Mirror Neuron Dysfunction in Autism Spectral Disorders. Cognitive Brain Research, 24, 190-198.

https://doi.org/10.1016/j.cogbrainres.2005.01.014

Oberman, L. M., \& Ramachandran, V. S. (2007). The Simulating Social Mind: The Role of the Mirror Neuron System and Simulation in the Social and Communicative Deficits of Autism Spectrum Disorders. Psychological Bulletin, 133, 310-327. https://doi.org/10.1037/0033-2909.133.2.310

Oberman, L. M., Ramachandran, V. S., \& Pineda, J. A. (2008). Modulation of Mu suppression in Children with Autism Spectrum Disorders in Response to Familiar or Unfamiliar Stimuli: The Mirror Neuron Hypothesis. Neuropsychologia, 46, 1558-1565. https://doi.org/10.1016/j.neuropsychologia.2008.01.010

Perkins, T., Stokes, M., McGillivray, J., \& Bittar, R. (2010). Mirror Neuron Dysfunction in Autism Spectrum Disorders. Journal of Clinical Neuroscience, 17, 1239-1243. https://doi.org/10.1016/j.jocn.2010.01.026

Pinheiro, M., Ivandic, I., \& Razzouk, D. (2017). The Economic Impact of Mental Disorders and Mental Health Problems in the Workplace. In D. Razzouk (ed.), Mental Health Economics, Cham: Springer. https://doi.org/10.1007/978-3-319-55266-8_28

Reichler, R. J., \& Schopler, E. (1976). Developmental Therapy: A Program Model for Providing Individual Services in the Community. In E. Schopler, \& R.J. Reichler (Eds.), Psychopathology and Child Development (pp. 347-372). Boston, MA: Springer. https://doi.org/10.1007/978-1-4684-2187-3_21

Rice, C. (2013). Time Trends in Diagnosis. In F. Volkmar (Ed.), Encyclopedia of Autism Spectrum Disorders (pp. 3120-3125). New York, NY: Springer. https://doi.org/10.1007/978-1-4419-1698-3_14

Rice, C. E., Rosanoff, M., Dawson, G., Durkin, M. S., Croen, L. A., Singer, A., \& Yeargin-Allsopp, M. (2013). Evaluating Changes in the Prevalence of the Autism Spectrum Disorders (ASDs). Public Health Review, 34, Article No. 17. https://doi.org/10.1007/BF03391685

Rizzolatti, G., \& Craighero, L. (2004). The Mirror-Neuron System. Annual Review of Neuroscience, 27, 169-192. https://doi.org/10.1146/annurev.neuro.27.070203.144230

Schalock, R. L. (2005). Introduction and Overview of the Special Issues on Quality of Life. Journal of Intellectual Disability Research, 49, 695-698. https://doi.org/10.1111/j.1365-2788.2005.00737.x

Schalock, R. L., Brown, I., Brown, R., Cummins, R. A., Felce, D., Matikka, L., Keith, K. D., \& Parmenter T. (2002). Conceptualization, Measurement, and Application of Quality of Life for Persons with Intellectual Disabilities: Report of an International Panel of Experts. Mental Retardation, 40, 457-470. https://doi.org/10.1352/0047-6765(2002)040<0457:CMAAOQ >2.0.CO;2

Schieve, L. A., Rice, C., Devine, O., Maenner, M. J., Lee, L. C., Fitzgerald, R., Wingate, M. 
S., Schendel, D., Pettygrove, S., \& van Naarden Braun, K. (2011). Have Secular Changes in Perinatal Risk Factors Contributed to the Recent Autism Prevalence Increase? Development and Application of a Mathematical Assessment Model. Annals of Epidemiology, 21, 930-945. https://doi.org/10.1016/j.annepidem.2011.08.009

Siebes, R., Muntjewerff, J. W., \& Staal, W. (2018). Differences of Symptom Distribution Across Adult Age in High Functioning Individuals on the Autism Spectrum Using Subscales of the Autism Spectrum Quotient. Journal of Autism and Developmental Disorders, 48, 3939-3944. https://doi.org/10.1007/s10803-018-3657-z

Stoppelbein, L., Biasini, F., Pennick, M., \& Greenin, L. (2016). Predicting Internalizing and Externalizing Symptoms among Children Diagnosed with an Autism Spectrum Disorder: The Role of Routines. Journal of Child and Family Studies, 25, 251-261. https://doi.org/10.1007/s10826-015-0218-3

Torrado, J. C., Gomez, J., \& Montoro, G. (2017). Emotional Self-Regulation of Individuals with Autism Spectrum Disorders: Smart Watches for Monitoring and Interaction. Sensors, 17, 1359. https://doi.org/10.3390/s17061359

Trautmann, S., Rehm, J., \& Wittchen, H. (2016). The Economic Costs of Mental Disorders: Do Our Societies React Appropriately to the Burden of Mental Disorders? EMBO Reports, 17, 1245-1249. https://doi.org/10.15252/embr.201642951

Verdugo, M. A., Schalock, R. L., Keith, K. D. Y., \& Stancliffe, R. (2005). Quality of Life and Its Measurement: Important Principles and Guidelines. Journal of Intellectual Disability Research, 49, 707-717. https://doi.org/10.1111/j.1365-2788.2005.00739.x

World Health Organization (2006). Economic Aspects of the Mental Health System: Key Messages to Health Planners and Policy-Makers. WHO/MSD/MER/06.2, Geneva: World Health Organization.

Wang, Y., \& Hamilton, A. F. (2012). Social Top-Down Response Modulation (STORM): A Model of the Control of Mimicry in Social Interaction. Frontiers in Human Neuroscience, 6, 153. https://doi.org/10.3389/fnhum.2012.00153

Wing, L., \& Potter, D. (2002). The Epidemiology of Autistic Spectrum Disorders: Is the Prevalence Rising? Mental Retardation and Developmental Disabilities Research Reviews, 8, 151-161. https://doi.org/10.1002/mrdd.10029

Wolstencroft, J., Robinson, L., Srinivasan, R., Kerry, E., Mandy, W., \& Skuse, D. (2018). A Systematic Review of Group Social Skills Interventions, and Meta-Analysis of Outcomes, for Children with High Functioning ASD. Journal of Autism and Developmental Disorders, 48, 2293-2307. https://doi.org/10.1007/s10803-018-3485-1

Yates, L., \& Hobson, H. (2020). Continuing to Look in the Mirror: A Review of Neuro Scientific Evidence for the Broken Mirror Hypothesis, EP-M Model and STORM Model of Autism Spectrum Conditions. Autism, 24, 1945-1959.

https://doi.org/10.1177/1362361320936945

Zimmerman, D., Ownsworth, T., O’Donovan, A., Roberts, J., \& Gullo, M. J. (2018). High Functioning Autism Spectrum Disorder in Adulthood: A Systematic Review of Factors Related to Psychosocial Outcomes. Journal of Intellectual \& Developmental Disability, 43, 2-19. https://doi.org/10.3109/13668250.2016.1262010 